\title{
What is the optimal timing to perform surgical stabilization of rib fractures?
}

\author{
Jonne T. H. Prins ${ }^{1} \wedge$, Mathieu M. E. Wijffels ${ }^{2} \wedge$, Fredric M. Pieracci ${ }^{1}$ \\ ${ }^{1}$ Department of Surgery, Denver Health Hospital \& Authority, University of Colorado School of Medicine, Denver, CO, USA; ${ }^{2}$ Trauma Research \\ Unit Department of Surgery, Erasmus University Medical Center, Rotterdam, The Netherlands \\ Contributions: (I) Conception and design: All authors; (II) Administrative support: JTH Prins; (III) Provision of study materials or patients: All \\ authors; (IV) Collection and assembly of data: JTH Prins; (V) Data analysis and interpretation: All authors; (VI) Manuscript writing: All authors; (VII) \\ Final approval of manuscript: All authors. \\ Correspondence to: Jonne T. H. Prins, MD. Department of Surgery, Denver Health and Hospital Authority, 777 Bannock Street MC 0206, Denver, \\ 80204 CO, USA. Email: j.prins@erasmusmc.nl.
}

\begin{abstract}
The practice of surgical stabilization of rib fractures (SSRF) for severe chest wall injury has exponentially increased over the last decade due to improved outcomes as compared to nonoperative management. However, regarding in-hospital outcomes, the ideal time from injury to SSRF remains a matter of debate. This review aims to evaluate and summarize currently available literature related to timing of SSRF. Nine studies on the effect of time to SSRF were identified. All were retrospective comparative studies with no detailed information on why patients underwent early or later SSRF. Patients underwent SSRF most often for a flail chest or $\geq 3$ displaced rib fractures. Early SSRF ( $\leq 48-72$ hours after admission) was associated with shorter hospital and intensive care unit length of stay (HLOS and ICU-LOS, respectively), duration of mechanical ventilation (DMV), and lower rates of pneumonia, and tracheostomy as well as lower hospitalization costs. No difference between early or late SSRF was demonstrated for mortality rate. As compared to nonoperative management, late SSRF ( $>3$ days after admission), was associated with similar or worse in-hospital outcomes. The optimal time to perform SSRF in patients with severe chest wall injury is early ( $\leq 48-72$ hours after admission) and associated with improved in-hospital outcomes as compared to either late salvage or nonoperative management. These data must however be cautiously interpreted due the retrospective nature of the studies and potential selection and attrition bias. Future research should focus on both factors and pathways that allow patients to undergo early SSRF.
\end{abstract}

Keywords: Rib fracture; surgical stabilization of rib fractures (SSRF); timing; early fixation

Submitted Apr 13, 2021. Accepted for publication Jul 13, 2021.

doi: 10.21037/jtd-21-649

View this article at: https://dx.doi.org/10.21037/jtd-21-649

\section{Introduction}

Thoracic trauma is the second leading cause of mortality after head trauma and accounts for $25 \%$ of injury-related deaths annually $(1,2)$. Rib fractures are common and present in $10 \%$ of trauma admissions and with rates up to $40 \%$ the most common injury following thoracic trauma (2-5). In addition, rib fractures are a marker of severe injury $(6,7)$. The gold standard for diagnoses and delineation of rib fractures is chest computed tomography (CT) which finds on average three additional rib fractures as compared to traditional chest radiography (8-11). Traumatic rib fractures often occur following high-energy trauma in younger patients, whereas more than half of elderly patients ( $\geq 65$ years) sustain rib fractures after low-energy trauma such as a ground

^ ORCID: Jonne T. H. Prins, 0000-0001-5782-9520; Mathieu M. E. Wijffels, 0000-0003-0423-4675. 
level fall $(12,13)$. There is a clear association between rib fractures and adverse outcomes. Not only the presence of rib fractures but also an increasing number of rib fractures is associated with mortality and pulmonary complications such as pneumonia $(4,14-18)$. In elderly patients this effect is even more prominent with 2- to 5-fold higher mortality rates as compared to younger patients with rib fractures and an increase in the mortality rate of $19 \%$ for each additionally fractured rib $(12,19,20)$. Furthermore, the degree of rib fracture dislocation has been associated with more severe concurrent thoracic trauma such as parenchymal injuries or pneumohemothorax, pulmonary complications and opioid requirement (21-23). In the long-term, sustaining rib fractures has been associated with chronic pain, disability, and decreased quality of life (24-28). Historically, rib fractures have been managed nonoperatively. Nonoperative treatment includes multimodal pain management, oxygen support or mechanical ventilation if required, and pulmonary physical therapy such as incentive spirometry (29). Even with improved critical care technology and widespread adoption of adjunctive pain management techniques, outcomes after multiple severe rib fractures have not significantly improved over the past 15 years (30). To date, the practice of rib fixation or surgical stabilization of rib fractures (SSRF) has increased exponentially and is now implemented in most international Trauma Centers (31-35). Despite increased use, many controversies within the field of SSRF remain. One such controversy surrounds the optimal time from injury to surgery. Two practice management guidelines for SSRF suggest early operative fixation to improve in-hospital outcomes $(36,37)$. However, literature on the optimal timing to SSRF is scarce. This review aimed to evaluate and summarize current available evidence related to timing of SSRF.

\section{SSRF}

The effect of SSRF has been studied using a variety of techniques, including wire cerclages, absorbable plates or Judet struts, but, to date, plating the outer cortex of the rib with bicortical screws is the most commonly employed technique $(38,39)$. This procedure often comprises standardized components such as, but not limited to, muscle sparing or minimally invasive incisions, fiberoptic bronchoscopy, video-assisted thoracoscopic surgery (VATS), pleural irrigation, and chest tube placement $(40,41)$. Simultaneously, an evolution in practice patterns has come with the increase of the practice of SSRF. More recently, implementation of intra-operative cryoablation of the intercostal nerves or complete thoracoscopic SSRF have been described (42-44).

In trauma, the use of SSRF first established ground in the treatment of patients with a flail chest. Several randomized controlled trials and multiple systematic reviews and metaanalysis have demonstrated a benefit of SSRF as compared to nonoperative management in terms of pneumonia rate, duration of mechanical ventilation (DMV), hospital and intensive care unit length of stay (HLOS and ICULOS, respectively), and cost-effectiveness (45-54). As a result, consensus guidelines by among others the Eastern Association for the Surgery of Trauma (EAST) and the Chest Wall Injury Society (CWIS) now recommend SSRF in patients with a flail chest $(36,37)$. Over the last years, the indications for SSRF extended. For example, literature on patients with non-flail fracture patterns shows improved short-term outcomes associated with SSRF in these patients with for example multiple severely dislocated rib fractures (40,55-58). In addition, traditional contraindications for SSRF, such as traumatic brain injury (TBI), age, or severe pulmonary contusion, are narrowing as SSRF has been shown to be a safe procedure in these patients and has even been correlated with improved outcomes in select patients (59-61). Long-term outcomes following SSRF have been studied less commonly with studies showing long-term pulmonary function and quality of life to recover to values within normal, but no significant benefit has been demonstrated compared to nonoperative management (62-66).

\section{Theoretical rationale}

In orthopedics, data supports early fracture fixation (24 to 48 hours after admission) with improved in-hospital outcomes as compared to late fixation cohorts (67-69). In case of hip fractures, early fixation is associated with shorter HLOS, lower mortality, pain, and complications such as pneumonia, pressure ulcers, and infection, which might be partially due to earlier out of bed mobilization $(68,69)$. In patients with open fractures of the tibia and femur, early stabilization is paramount to restore alignment of the limb, eliminate movement and fracture overlap, diminish further softtissue damage, and decrease the risk of bacterial spread (70). For polytraumatized patients with pelvic, acetabulum, femur or spine fractures, early fixation is advocated because of a lower risk of pulmonary complications and multiple organ failure as compared to late surgery (71). When severe head trauma [Glasgow Coma Scale (GCS), <9] is present in 
Table 1 Contraindications to early SSRF
1. Hemodynamic instability
2. Other high priority injuries (e.g., spine fractures)*
3. Intracranial hypertension
4. Inability to properly position patient (e.g., open abdomen, pelvic fixator)
5. Pleural empyema
6. Severe chest wall tissue loss

*, the CWIS practice management guidelines advocate for a combined approach with a spine team in those patients with spine fractures that require operative fixation (59). SSRF, surgical stabilization of rib fractures; CWIS, Chest Wall Injury Society.

patients with major orthopedic fractures, early aggressive stabilization of these fractures is recommended if sufficient cerebral perfusion pressure can be maintained as this might prevent additional secondary brain injury due to hypotension, but available studies are of low quality (72).

The optimal timing to perform SSRF is debated, but, in general, believed to be rather early than late in patients without contra-indications who are deemed stable for surgery (Table 1). Because the ribs are intimately associated with respiration, it is impossible to immobilize them in an effective, nonoperative fashion without impacting pulmonary mechanics. Furthermore, rib fracture pain during respiration results in splinting and ineffective secretion clearance, both of which begin immediately following the injury and, over time, act in a cumulative fashion to place patients at a possibly increased risk for respiratory failure. The earlier these factors can be mitigated by stabilization, the earlier this risk is theoretically minimized.

One traditional SSRF indication is the failure of nonoperative management or the development of progressive pain or respiratory insufficiency. Advocates of this indication believe that primary nonoperative treatment avoids an unnecessary surgery. However, as mentioned, debilitating pulmonary morbidity rates including pneumonia, retained hemothorax, or empyema remain high in these patients and possibly precede this nonoperative management failure, whereas SSRF might have potentially prevented these complications $(55,73,74)$. In addition, early SSRF creates an opportunity to clear the pleural space and place guided loco-regional anesthesia. Furthermore, tissue inflammation and edema of both lung parenchyma and thoracic wall soft tissue peak at approximately 72 hours after injury with dissection often being bloodier and more challenging as compared to early SSRF (75). Also, hardware implantation in patients who have had recent pneumonia or empyema might lead to infected hardware, often requiring an additional operative procedure of implant removal $(76,77)$. Practice patterns and consensus statements appear to be shifting towards early SSRF.

\section{Literature review}

Currently, there have been nine studies specifically addressing the effect of timing on outcomes after SSRF (Table 2). The earliest of these studies was a retrospective single center cohort study comparing patients who underwent SSRF $(n=22)$ with a matched cohort of nonoperatively managed patients $(n=28)$ (78). Indications for SSRF were a radiographic or clinical flail chest, and pulmonary hernia. The SSRF group consisted of $17(77.3 \%)$ male patients with a mean age of 48 years with a mean ISS of 25 and 6 rib fractures. Patients underwent SSRF with $2.7 \mathrm{~mm}$ locking reconstruction plates and mean operative time of 55 minutes at a mean of 2.3 (range, 1-5) days after injury. The total cohort had a follow-up time of 17.8 (range, 13-22) months during which no cases of hardware failure, surgical site infection, or nonunion were reported. In regression analysis, shorter time to SSRF was associated with decreased HLOS, ICU-LOS and DMV.

The following study was a retrospective single center cohort study of 102 patients, stratified by time to SSRF (early, $\leq 48$ hours or late, $>48$ hours) (79). Patients with a flail chest or $\geq 3$ displaced rib fractures were considered for SSRF, but patients with chest wall deformity, inadequate analgesia, hemopneumothorax, or increasing ventilatory support when intubated, were also assessed for SSRF candidacy. A multidisciplinary team decided if patients should require SSRF and aimed to perform the procedure as soon as possible. Patients underwent SSRF with precontoured titanium rib fracture plates at 2 (range, 0-16) days 


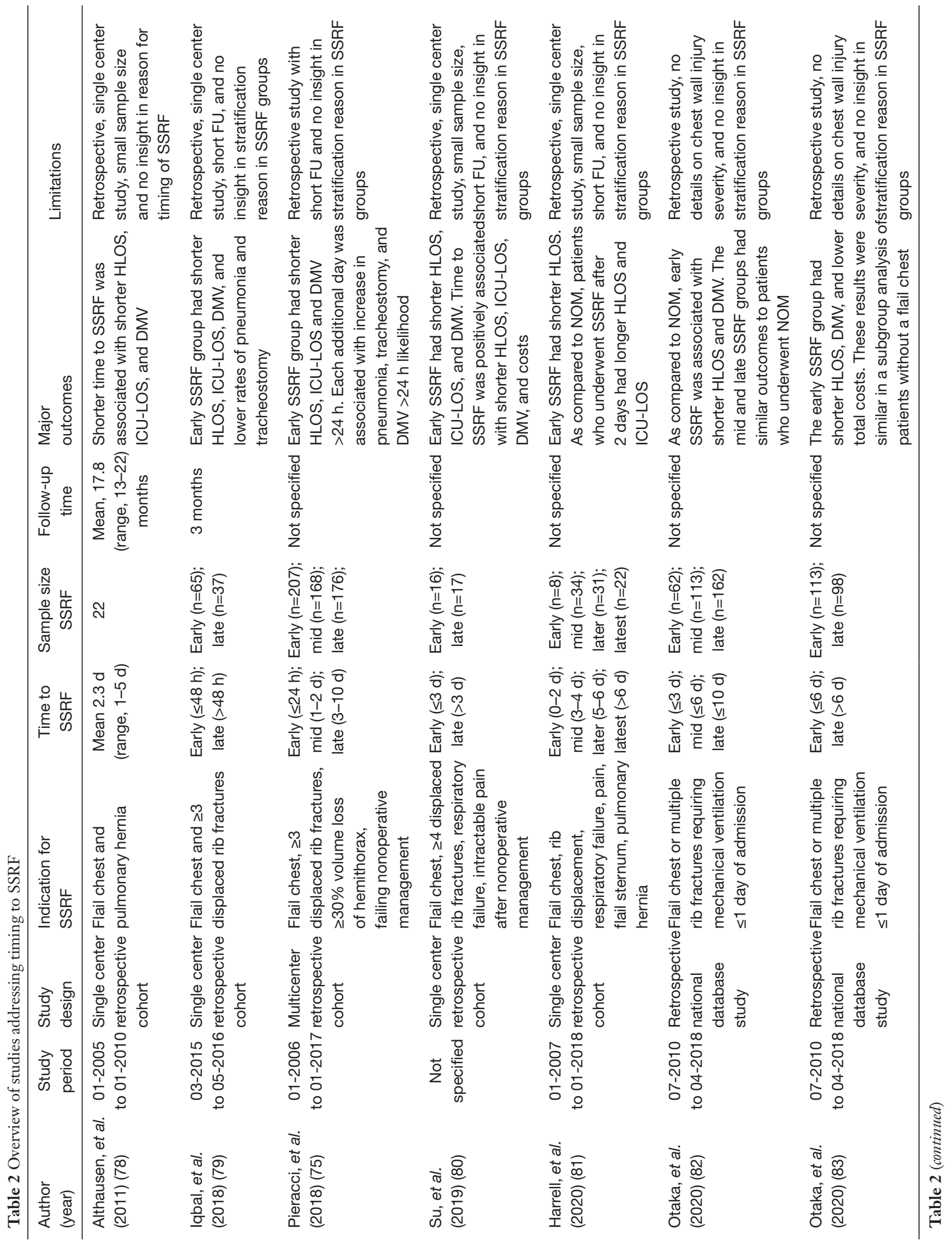




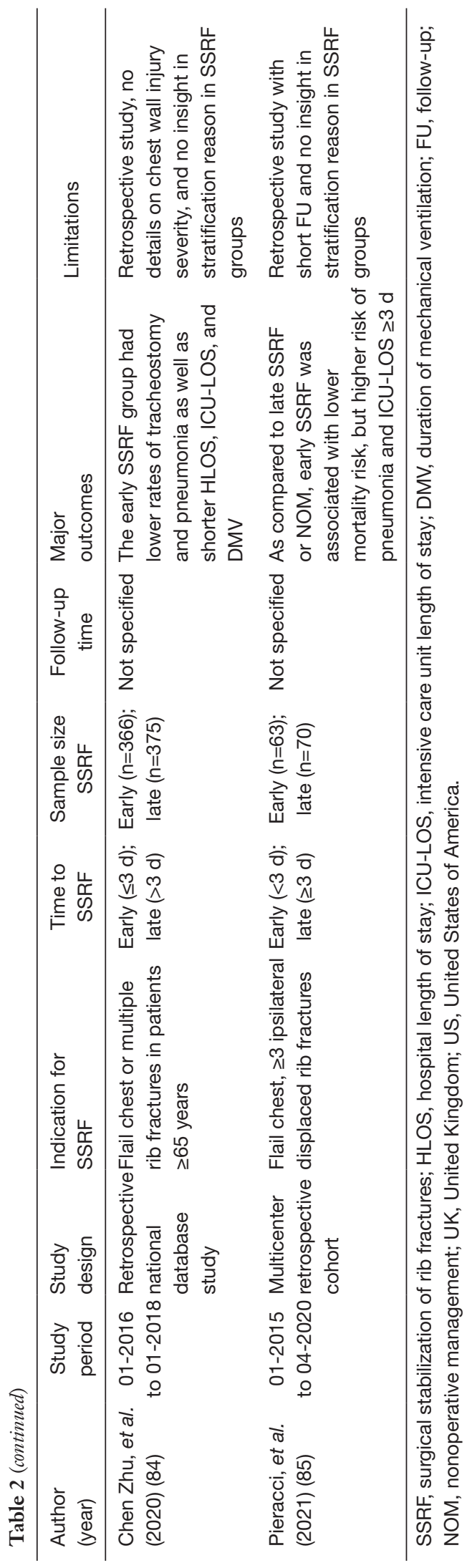

after admission. The groups had similar sex, ISS, and presence of flail chest, hemopneumothorax, and additional non-chest injuries, but the early SSRF group was younger. The early SSRF group had significantly shorter HLOS (11.5 versus 17.3 days; $\mathrm{P}=0.008)$, ICU-LOS (3.3 versus 7.1 days; $\mathrm{P}=0.01$ ), and $\mathrm{DMV}$ (4.8 versus 2.0 days; $\mathrm{P}=0.03$ ), and decreased rate of pneumonia $(n=11,17 \%$ versus $n=18$, $49 \% ; \mathrm{P}=0.001)$, and tracheostomy $(\mathrm{n}=4,6 \%$ versus $\mathrm{n}=8$, $22 \% ; \mathrm{P}=0.02)$. The mortality rate was similar between groups.

The third study was a multicenter retrospective cohort study of 551 patients who underwent SSRF, stratified by timing to SSRF as early (day $0, \leq 24$ hours), mid (day $1-2$ ), or late (days 3-10) (75). The choice of rib fixation system was left to the discretion of the surgeon and operative time varied significantly by group and was shortest in the mid group (median, 122 minutes) and longest for the late group (median, 201 minutes; $\mathrm{P}<0.01$ ). Time to SSRF was significantly associated with study site, year of surgery, age, body mass index (BMI), and mechanism of injury. On univariate analysis, patients who underwent early SSRF had shorter HLOS, ICU-LOS and lower rate of DMV $>24$ hours. Rate of mortality, pneumonia, and tracheostomy did not differ between groups. Multivariable logistic regression showed that each additional day to SSRF was associated with an increased likelihood of $31 \%$ for pneumonia, $27 \%$ for DMV $>24$ hours, and $26 \%$ for tracheostomy.

The fourth study was a single center retrospective cohort study of 33 patients who underwent SSRF, stratified as early ( $\leq 3$ days) or late ( $>3$ days) (80). The two groups had similar age, BMI, sex, comorbidities, ISS, presence of flail chest, and associated injuries. Patients underwent SSRF with nonprecontoured 2.4 or $3.5 \mathrm{~mm}$ metal locking plates between 0 and 14 days after injury. Operative time was similar between groups. The early SSRF group had significantly shorter HLOS (12 versus 18 days; $\mathrm{P}=0.005$ ), ICU-LOS (123 versus 230 hours; $\mathrm{P}=0.005$ ), and DMV (36 versus 90 hours; $\mathrm{P}=0.03$ ). The rate of pneumonia, mortality, and total hospital costs were similar between groups. Multivariable regression analysis showed that time to SSRF was positively associated with shorter HLOS, ICU-LOS, DMV, and national health insurance costs.

The following study was a single center retrospective cohort study of 95 patients who underwent SSRF, stratified by number of hospital days to SSRF $(0-2,3-4,5-6$, and $>6$ days) (81). These SSRF groups were compared to patients who were treated nonoperatively, matched in a 1:2 ratio by 
age, ISS, AIS chest and head. Patients underwent SSRF with a non-specified fixation system with a mean operative time of 147 minutes on hospital day 5.5 (range, day 1-25). Over $35 \%$ of patients underwent SSRF for other indications than flail chest such as pain and rib displacement which were not further defined. As compared to the nonoperative group, the SSRF group had a significant higher number of rib fractures, pulmonary contusion, presence of flail chest, and history of smoking. Within the SSRF groups, patients who underwent early SSRF (0-2 days) had shorter HLOS than the other groups (11.8 versus 3-4 days: 12.6 versus 5-6 days: 13.4 versus $>6$ days: 19.6 days; $\mathrm{P}=0.003)$. As compared to nonoperative management, patients who underwent SSRF after day 2 had longer HLOS and ICU-LOS.

The sixth study was a retrospective national database study of 162 patients with rib fractures who required mechanical ventilation within 1 day of admission and underwent SSRF within 3, 6, or 10 days after admission (82). There was no information on rib fracture severity or operative characteristics. These SSRF groups were compared to patients who were treated nonoperatively, based on "overlap weighting", a propensity scoring method. After overlap weighting, there were no differences between groups in baseline and injury characteristics. On adjusted analysis, patients who underwent SSRF within 3 days had shorter HLOS and DMV than nonoperatively treated patients. The rates of pneumonia, tracheostomy, and mortality were similar. There were no significant differences in all outcomes between patients who underwent nonoperative management and those who underwent SSRF within 6 or 10 days after admission.

The next study was a retrospective national database study of the same time period and patient population as the previous study (83). In this study $(\mathrm{n}=211)$, patients who underwent SSRF were stratified based on the median time to SSRF in $\leq 6$ and $>6$ days (no range given) following admission. There was no information on rib fracture severity or operative characteristics. Patients in the $\leq 6$ days group were more often male, and more often had a higher GCS score, and flail chest. Propensity score matching was performed to compare outcomes between the two groups. On adjusted analysis, patients who underwent SSRF within 6 days had shorter HLOS (percent difference, -27.1, $95 \% \mathrm{CI},-40.0$ to $-11.5 ; \mathrm{P}=0.001)$, DMV $(-34.1,95 \%$ CI, -53.8 to $-6.2 ; \mathrm{P}=0.02$, and lower total hospitalization costs $(-28.4,95 \% \mathrm{CI},-38.4$ to $-16.9 ; \mathrm{P}<0.001)$. The rates of tracheostomy, pneumonia, and mortality were similar between groups.
The eighth study on timing to SSRF was a retrospective study of the Trauma Quality Improvement Program database comparing patients $\geq 65$ years who underwent SSRF to nonoperatively treated elderly patients (84). A subgroup analysis was performed of 741 patients who underwent SSRF, stratified as early ( $\leq 3$ days) or late ( $>3$ days). While injury characteristics such as ISS and chest AIS were known, no detailed information on rib fracture severity or SSRF characteristics was available. The early SSRF group had a higher rate of male patients and lower rate of intubation on ED arrival. After propensity score matching, the early SSRF group had lower rates of tracheostomy $(6.6 \%$ versus $15.5 \% ; \mathrm{P}<0.001)$ and ventilatorassociated pneumonia $(0.8 \%$ versus $4.8 \% ; \mathrm{P}<0.001)$ and shorter HLOS (10 versus 15 days; $\mathrm{P}<0.001)$, ICU-LOS (6 versus 10 days; $\mathrm{P}<0.001$ ), and $\mathrm{DMV}$ (4 versus 8 days; $\mathrm{P}<0.001)$ as compared to the late SSRF group. There was no difference in mortality rate.

The most recent study is by the senior author of this review (85). This was a retrospective multicenter study comparing patients aged 80 years or older who underwent SSRF ( $n=133$ ) with a matched cohort of nonoperatively managed patients $(n=227)$. Indications for SSRF were radiographic flail segment and/or $\geq 3$ ipsilateral, displaced rib fractures. The choice of rib fixation system was left to the discretion of the surgeon. Patients underwent SSRF at a median of 3 days after injury and operative time was 115 (range, 92-161) minutes. Chest wall injury severity and likelihood of additional urgent procedures were similar between groups. On multivariable logistic regression, early SSRF was associated with lower mortality but also associated with a higher risk of pneumonia and ICULOS $\geq 3$ days, as compared to late SSRF or nonoperative management. This was hypothesized to be attributable to survivor bias, inadequate control of associated injuries, variability in practice across centers, and invasive impact of intubation and tissue trauma of SSRF in this frail population. Subgroup analysis was performed for patients who underwent SSRF $<72$ versus $\geq 72$ hours. The early SSRF group was older, more likely to be women, and had a lower BMI. In this analysis, there was no observed benefit to early $v s$. late surgery.

\section{Logistical considerations}

While some studies were able to correct for patient- and injury characteristics when analyzing outcomes, many other factors might also confound time from admission to 
the operative room (OR). In these retrospective studies, it is difficult to grasp what affects getting the patient to the OR besides characteristics available on chart review. The time to theatre might for example be delayed by associated comorbidities including cardiac problems, medication use such as anticoagulation, or higher priority injuries requiring immediate operative or invasive repair (86) .

In addition to the hypothesized patient- and injury characteristics which might preclude SSRF, logistical considerations might also be of significance. For example, admission delay from emergency department to hospitalization due to shortage of beds, delayed diagnosis, or OR availability might affect time to surgery and negatively affect outcome (87). It is possible that the shift to earlier SSRF over the years might have to do with increased familiarity with this procedure. Whereas OR access might have been limited in the first years of implementation, a subtle shift might occur over the years, allowing OR access at a lower threshold for a known service. In line with implementation of a new procedure, there might not be a trained surgeon available to perform SSRF at any moment during the night or weekends. Furthermore, a relatively novel practice such as SSRF or aspects of it (e.g., bronchoscopy) might not be considered standard of care in its early years. As a result of this unfamiliarity, it might be more difficult to gain approval from Institutional Review Boards to conduct high quality research such as randomized controlled trials to strengthen the benefit of a new procedure or get informed consent from the patient or family to perform SSRF (88).

\section{Comments}

Current practice management guidelines for SSRF both advocate early operative fixation ( $\leq 72$ hours, once other lifethreatening injuries have been identified and stabilized) to reduce HLOS, ICU-LOS, DMV, and rate of mechanical ventilation requirement, pneumonia, and tracheostomy $(36,37)$. While only the first study was available at the time of developing these guidelines, the more recently published studies corroborate this consensus of early SSRF benefit $(75,78-80,82-84,89)$. In addition, early SSRF appears to be safe and also beneficial in elderly patients for all outcomes and is associated with lower hospitalization costs $(80,83,84)$. Interestingly, recent studies have also suggested that while early fixation within 2-3 days after admission is associated with improved in-hospital outcomes, performing SSRF after this time period might actually correlate with outcomes inferior to nonoperative management $(81,82)$. This might be associated to exposing the patient to the risks of surgery without the benefit of early fixation such as improving chest wall stability, evacuation of hemothorax or trans positioned chest wall tissue, and possible prevention of pneumonia and a lengthy hospitalization. Furthermore, no association between time to SSRF and mortality rate was demonstrated in any of the studies.

There are several methodologic considerations when interpreting this data addressing optimal timing of SSRF. The first is selection bias. While most studies tried to adjust for covariates, in general, patients who are selected for early SSRF are often less severely injured. Thus, any observed improved outcomes might be due to the patient's associated injuries or lack thereof. A second limitation is attrition bias. This comprises patients who are initially considered for surgery but improve after observation and are discharged following nonoperative treatment. By contrast, patients who deteriorate after an uncomplicated period of observation might ultimately undergo SSRF late in their hospitalization and represent the late SSRF group. While the first example of attrition bias results might affect the nonoperative group which was studied in two of the abovementioned studies $(81,82)$, the second example possibly affects the late SSRF groups in all studies. The missing piece of information in all reviewed studies to overcome this bias is an overview of the reasons for stratification of these patients in either the early or later SSRF groups. Hypothetical reasons can be injury severity, logistic reasons as surgeon, operating room, and fixation system availability, and patient or surgeon preference. Furthermore, all studies were retrospective with most follow-up time limited to index hospitalization, and often either small sample sizes or no insight in chest wall injury severity. Also, only one study controlled for study year which could confound outcomes as complication rates or other in-hospital outcomes tend to improve over time after implementation of a relatively novel procedure such as $\operatorname{SSRF}(75,90)$.

The authors' practice pattern is derived from the study by the senior author and includes early performance of SSRF, ideally within 24 hours of admission if there are no contraindications present (Table 1) (75). The SSRF procedure has been standardized to include general anesthesia, fiberoptic bronchoscopy, muscle sparing incisions, VATS-inspection of the thorax, evacuation of retained hemothorax, pleural irrigation, chest tube placement, and lately, an injection of locoregional intercostal nerve analgesia. It is believed that these adjunctive maneuvers positively impact the 

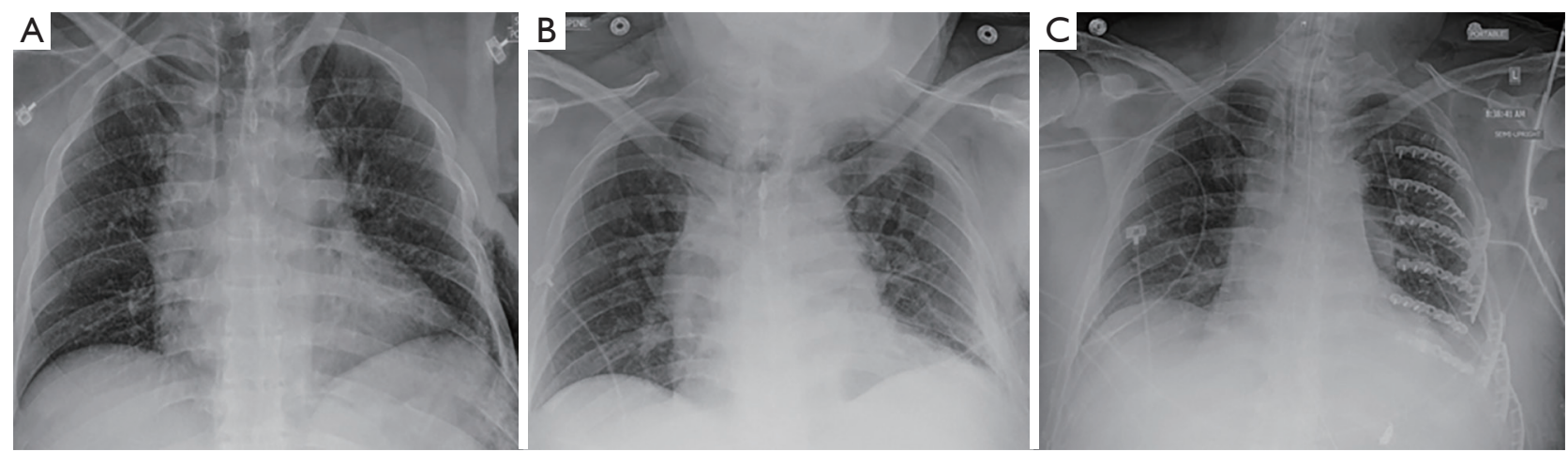

Figure 1 Initial chest radiography (A) of a 55-year-old male who sustained left 4-9 rib fractures which were nondisplaced. Chest radiography of the same patient 24 hours after ICU admission (B) showing interval rib fracture displacement. Chest radiography after SSRF (C) during which this patient received 11 plates to restore chest wall stability. ICU, intensive care unit; SSRF, surgical stabilization of rib fractures.
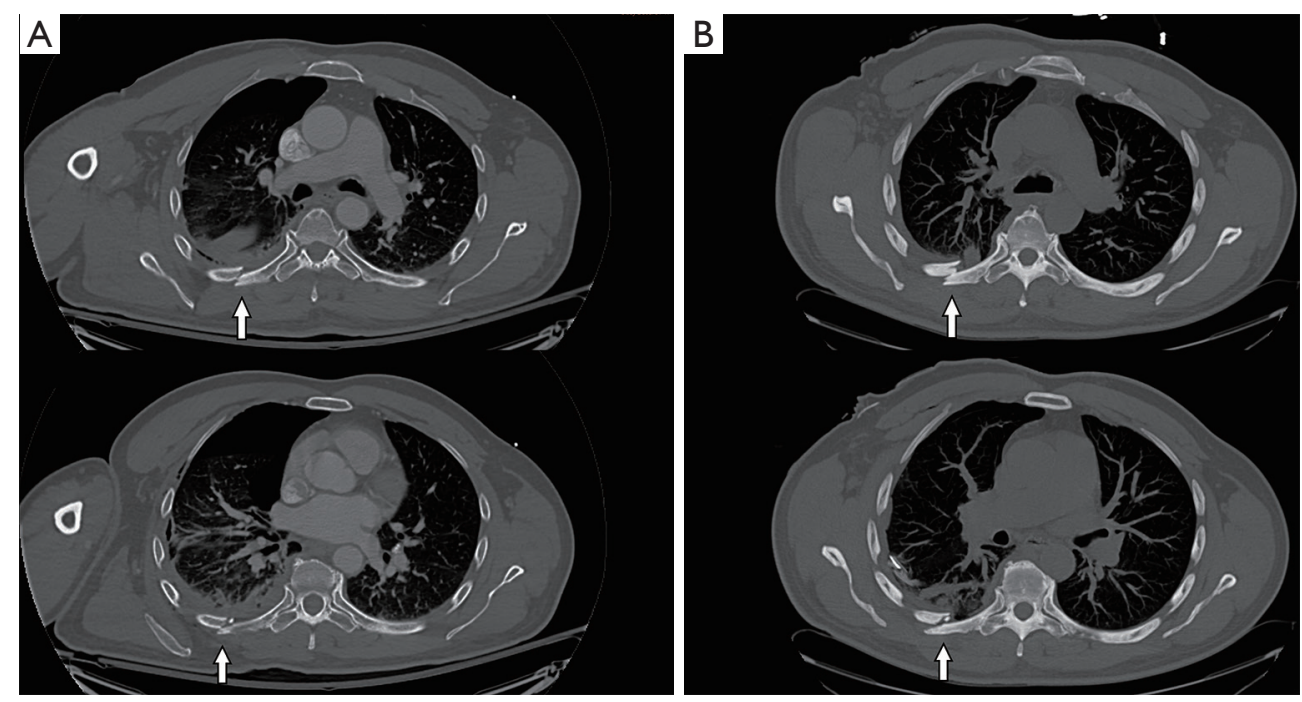

Figure 2 Initial chest CT displaying two offset posterior fractures of rib six and seven (A). After two days, a repeat chest CT showed interval rib fracture displacement of these same fractures (B). CT, computed tomography.

patients' recovery, pain level, and decrease the likelihood of the development of pneumonia, retained hemothorax or empyema, and respiratory failure. Also, interval rib fracture displacement has been previously described in the rib fracture literature and incidentally experienced by the authors in patients who were initially not deemed SSRF candidates but developed severe interval rib fracture displacement along fracture lines which thus increased chest wall instability, pain, and risk for pulmonary morbidity (91). This interval displacement can be discovered by comparing sequential chest radiography, but it is unclear in how many patients this occurs following trauma or which patients are at risk (Figure 1). A prospective study on the rate of interval rib fracture displacement in terms of rib fracture taxonomy and impact on in-hospital outcomes is now being conducted at the authors' institution (Figure 2).

Over the decade of implementation of this procedure, average time from admission to SSRF in the senior author's center has decreased from 2 days to within 24 hours, which is most likely multifactorial. First, the aforementioned studies and guidelines have advocated a clinical benefit to early SSRF. Second, the contention is that, as case volume and experience with SSRF increases, there is an increased familiarity with the procedure by operating room staff. 
Third, as staff becomes more familiar with the operation, a subtle shift may occur, allowing quicker $\mathrm{OR}$ access for a known instead of novel service.

\section{Conclusions}

In line with current guidelines and consensus, increasing amounts of data support the benefit of early $(\leq 48-72$ hours after admission) SSRF in properly selected stable patients as compared to late salvage SSRF. Performing early SSRF is associated with reduced HLOS, ICU-LOS, and DMV, as well as lower hospitalization costs and rates of pneumonia and tracheostomy. These data must however be interpreted with caution and attention to potential selection and attrition bias. The current studies are all retrospective with often small sample sizes and short follow-up. The authors' practices aim to perform SSRF as soon as possible and ideally within the first 24 hours after injury. The current exponential increase in number of SSRF cases performed and international collaborations should accommodate the possibility to perform sufficiently powered analyses of the effect of timing of SSRF on both acute and long-term outcomes.

\section{Acknowledgments}

Funding: None.

\section{Footnote}

Provenance and Peer Review: This article was commissioned by the Guest Editors (Alessandro Brunelli and Enrico Ruffini) for the series "European Perspectives in Thoracic Surgery (2020) - the Seven Edition" published in fournal of Thoracic Disease. The article has undergone external peer review.

Conflicts of Interest: All authors have completed the ICMJE uniform disclosure form (available at https:// dx.doi.org/10.21037/jtd-21-649). The series "European Perspectives in Thoracic Surgery (2020) - the Seven Edition" was commissioned by the editorial office without any funding or sponsorship. MMEW is a lecturer and ad hoc consultant for Johnson \& Johnson DePuy Synthes and has received a research grant outside the submitted work from an association sponsored by Stryker. The authors have no other conflicts of interest to declare.

Ethical Statement: The authors are accountable for all aspects of the work in ensuring that questions related to the accuracy or integrity of any part of the work are appropriately investigated and resolved.

Open Access Statement: This is an Open Access article distributed in accordance with the Creative Commons Attribution-NonCommercial-NoDerivs 4.0 International License (CC BY-NC-ND 4.0), which permits the noncommercial replication and distribution of the article with the strict proviso that no changes or edits are made and the original work is properly cited (including links to both the formal publication through the relevant DOI and the license). See: https://creativecommons.org/licenses/by-nc-nd/4.0/.

\section{References}

1. Ziegler DW, Agarwal NN. The morbidity and mortality of rib fractures. J Trauma 1994;37:975-9.

2. Lafferty PM, Anavian J, Will RE, et al. Operative treatment of chest wall injuries: indications, technique, and outcomes. J Bone Joint Surg Am 2011;93:97-110.

3. Cameron P, Dziukas L, Hadj A, et al. Rib fractures in major trauma. Aust N Z J Surg 1996;66:530-4.

4. Flagel BT, Luchette FA, Reed RL, et al. Half-a-dozen ribs: the breakpoint for mortality. Surgery 2005;138:717-23; discussion 723-5.

5. Schulz-Drost S, Oppel P, Grupp S, et al. Bony injuries of the thoracic cage in multiple trauma: Incidence, concomitant injuries, course and outcome. Unfallchirurg 2016;119:1023-30.

6. Michetti CP, Fakhry SM, Brasel K, et al. Trauma ICU Prevalence Project: the diversity of surgical critical care. Trauma Surg Acute Care Open 2019;4:e000288.

7. Peek J, Ochen Y, Saillant N, et al. Traumatic rib fractures: a marker of severe injury. A nationwide study using the National Trauma Data Bank. Trauma Surg Acute Care Open 2020;5:e000441.

8. Murphy CE 4th, Raja AS, Baumann BM, et al. Rib Fracture Diagnosis in the Panscan Era. Ann Emerg Med 2017;70:904-9.

9. Chapman BC, Overbey DM, Tesfalidet F, et al. Clinical Utility of Chest Computed Tomography in Patients with Rib Fractures CT Chest and Rib Fractures. Arch Trauma Res 2016;5:e37070.

10. Livingston DH, Shogan B, John P, et al. CT diagnosis of Rib fractures and the prediction of acute respiratory failure. J Trauma 2008;64:905-11.

11. Singleton JM, Bilello LA, Canham LS, et al. Chest 
computed tomography imaging utility for radiographically occult rib fractures in elderly fall-injured patients. J

Trauma Acute Care Surg 2019;86:838-43.

12. Bulger EM, Arneson MA, Mock CN, et al. Rib fractures in the elderly. J Trauma 2000;48:1040-6; discussion 1046-7.

13. Barnea Y, Kashtan H, Skornick Y, et al. Isolated rib fractures in elderly patients: mortality and morbidity. Can J Surg 2002;45:43-6.

14. Hofman M, Andruszkow H, Kobbe P, et al. Incidence of post-traumatic pneumonia in poly-traumatized patients: identifying the role of traumatic brain injury and chest trauma. Eur J Trauma Emerg Surg 2020;46:11-9.

15. Coary R, Skerritt C, Carey A, et al. New horizons in rib fracture management in the older adult. Age Ageing 2020;49:161-7.

16. Lee RB, Bass SM, Morris JA Jr, et al. Three or more rib fractures as an indicator for transfer to a Level I trauma center: a population-based study. J Trauma 1990;30:689-94.

17. Battle CE, Hutchings H, Evans PA. Risk factors that predict mortality in patients with blunt chest wall trauma: a systematic review and meta-analysis. Injury 2012;43:8-17.

18. Battle C, Hutchings H, Lovett S, et al. Predicting outcomes after blunt chest wall trauma: development and external validation of a new prognostic model. Crit Care 2014;18:R98.

19. Bergeron E, Lavoie A, Clas D, et al. Elderly trauma patients with rib fractures are at greater risk of death and pneumonia. J Trauma 2003;54:478-85.

20. Van Vledder MG, Kwakernaak V, Hagenaars T, et al. Patterns of injury and outcomes in the elderly patient with rib fractures: a multicenter observational study. Eur J Trauma Emerg Surg 2019;45:575-83.

21. Parlak S, Beşler MS. Investigation of the relationship of the number, localization, and displacement of rib fractures with intrathoracic structures and abdominal solid organ complications using computed tomography. Eur J Trauma Emerg Surg 2020. [Epub ahead of print]. doi: 10.1007/ s00068-020-01547-2.

22. Bugaev N, Breeze JL, Alhazmi M, et al. Magnitude of rib fracture displacement predicts opioid requirements. J Trauma Acute Care Surg 2016;81:699-704.

23. Chien CY, Chen YH, Han ST, et al. The number of displaced rib fractures is more predictive for complications in chest trauma patients. Scand J Trauma Resusc Emerg Med 2017;25:19.

24. Shelat VG, Eileen S, John L, et al. Chronic pain and its impact on quality of life following a traumatic rib fracture. Eur J Trauma Emerg Surg 2012;38:451-5.

25. Marasco S, Lee G, Summerhayes R, et al. Quality of life after major trauma with multiple rib fractures. Injury 2015;46:61-5.

26. Kerr-Valentic MA, Arthur M, Mullins RJ, et al. Rib fracture pain and disability: can we do better? J Trauma 2003;54:1058-63; discussion 1063-4.

27. Mayberry JC, Kroeker AD, Ham LB, et al. Long-term morbidity, pain, and disability after repair of severe chest wall injuries. Am Surg 2009;75:389-94.

28. Gordy S, Fabricant L, Ham B, et al. The contribution of rib fractures to chronic pain and disability. Am J Surg 2014;207:659-62; discussion 662-3.

29. Wijffels MME, Prins JTH, Polinder S, et al. Early fixation versus conservative therapy of multiple, simple rib fractures (FixCon): protocol for a multicenter randomized controlled trial. World J Emerg Surg 2019;14:38.

30. Dehghan N, de Mestral C, McKee MD, et al. Flail chest injuries: a review of outcomes and treatment practices from the National Trauma Data Bank. J Trauma Acute Care Surg 2014;76:462-8.

31. de Moya M, Nirula R, Biffl W. Rib fixation: Who, What, When? Trauma Surg Acute Care Open 2017;2:e000059.

32. Rockne WY, Grigorian A, Christian A, et al. No difference in mortality between level I and level II trauma centers performing surgical stabilization of rib fracture. Am J Surg 2021;221:1076-81.

33. Kane ED, Jeremitsky E, Pieracci FM, et al. Surgical Stabilization of Rib Fractures: Increasing at an Alarming Rate? Oral Presentation at 47th Annual Meeting of the Western Trauma Association, 2017.

34. Kane ED, Jeremitsky E, Pieracci FM, et al. Quantifying and exploring the recent national increase in surgical stabilization of rib fractures. J Trauma Acute Care Surg 2017;83:1047-52.

35. Choi J, Kaghazchi A, Dickerson KL, et al. Heterogeneity in managing rib fractures across non-trauma and level I, II, and III trauma centers. Am J Surg 2021. [Epub ahead of print]. doi: 10.1016/j.amjsurg.2021.02.013.

36. Kasotakis G, Hasenboehler EA, Streib EW, et al. Operative fixation of rib fractures after blunt trauma: A practice management guideline from the Eastern Association for the Surgery of Trauma. J Trauma Acute Care Surg 2017;82:618-26.

37. Pieracci FM, Majercik S, Ali-Osman F, et al. Consensus statement: Surgical stabilization of rib fractures rib fracture colloquium clinical practice guidelines. Injury 
2017;48:307-21.

38. Bemelman M, Poeze M, Blokhuis TJ, et al. Historic overview of treatment techniques for rib fractures and flail chest. Eur J Trauma Emerg Surg 2010;36:407-15.

39. Nirula R, Diaz JJ Jr, Trunkey DD, et al. Rib fracture repair: indications, technical issues, and future directions. World J Surg 2009;33:14-22.

40. Pieracci FM, Rodil M, Stovall RT, et al. Surgical stabilization of severe rib fractures. J Trauma Acute Care Surg 2015;78:883-7.

41. Fokin AA, Hus N, Wycech J, et al. Surgical Stabilization of Rib Fractures: Indications, Techniques, and Pitfalls. JBJS Essent Surg Tech 2020;10:e0032.

42. Bauman ZM, Loftus J, Raposo-Hadley A, et al. Surgical stabilization of rib fractures combined with intercostal nerve cryoablation proves to be more cost effective by reducing hospital length of stay and narcotics. Injury 2021;52:1128-32.

43. Zhang J, Hong Q, Mo X, et al. Complete Video-assisted Thoracoscopic Surgery for Rib Fractures: A Series of 35 Cases. Ann Thorac Surg 2021. [Epub ahead of print]. doi: 10.1016/j.athoracsur.2021.01.065.

44. Pieracci FM. Completely thoracoscopic surgical stabilization of rib fractures: can it be done and is it worth it? J Thorac Dis 2019;11:S1061-9.

45. Tanaka H, Yukioka T, Yamaguti Y, et al. Surgical stabilization of internal pneumatic stabilization? A prospective randomized study of management of severe flail chest patients. J Trauma 2002;52:727-32; discussion 732 .

46. Granetzny A, Abd El-Aal M, Emam E, et al. Surgical versus conservative treatment of flail chest. Evaluation of the pulmonary status. Interact Cardiovasc Thorac Surg 2005;4:583-7.

47. Marasco SF, Davies AR, Cooper J, et al. Prospective randomized controlled trial of operative rib fixation in traumatic flail chest. J Am Coll Surg 2013;216:924-32.

48. Liu T, Liu P, Chen J, et al. A Randomized Controlled Trial of Surgical Rib Fixation in Polytrauma Patients With Flail Chest. J Surg Res 2019;242:223-30.

49. Cataneo AJ, Cataneo DC, de Oliveira FH, et al. Surgical versus nonsurgical interventions for flail chest. Cochrane Database Syst Rev 2015;(7):CD009919.

50. Schuurmans J, Goslings JC, Schepers T. Operative management versus non-operative management of rib fractures in flail chest injuries: a systematic review. Eur J Trauma Emerg Surg 2017;43:163-8.

51. Liang YS, Yu KC, Wong CS, et al. Does Surgery Reduce the Risk of Complications Among Patients with Multiple Rib Fractures? A Meta-analysis. Clin Orthop Relat Res 2019;477:193-205.

52. Swart E, Laratta J, Slobogean G, et al. Operative Treatment of Rib Fractures in Flail Chest Injuries: A Meta-analysis and Cost-Effectiveness Analysis. J Orthop Trauma 2017;31:64-70.

53. Slobogean GP, MacPherson CA, Sun T, et al. Surgical fixation vs nonoperative management of flail chest: a metaanalysis. J Am Coll Surg 2013;216:302-11.e1.

54. Leinicke JA, Elmore L, Freeman BD, et al. Operative management of rib fractures in the setting of flail chest: a systematic review and meta-analysis. Ann Surg 2013;258:914-21.

55. Pieracci FM, Leasia K, Bauman Z, et al. A multicenter, prospective, controlled clinical trial of surgical stabilization of rib fractures in patients with severe, nonflail fracture patterns (Chest Wall Injury Society NONFLAIL). J Trauma Acute Care Surg 2020;88:249-57.

56. Pieracci FM, Lin Y, Rodil M, et al. A prospective, controlled clinical evaluation of surgical stabilization of severe rib fractures. J Trauma Acute Care Surg 2016;80:187-94.

57. Wijffels MME, Prins JTH, Perpetua Alvino EJ, et al. Operative versus nonoperative treatment of multiple simple rib fractures: A systematic review and meta-analysis. Injury 2020;51:2368-78.

58. Choi J, Gomez GI, Kaghazchi A, et al. Surgical Stabilization of Rib Fracture to Mitigate Pulmonary Complication and Mortality: A Systematic Review and Bayesian Meta-Analysis. J Am Coll Surg 2021;232:211219.e2.

59. Pieracci FM, Agarwal S, Doben A, et al. Indications for surgical stabilization of rib fractures in patients without flail chest: surveyed opinions of members of the Chest Wall Injury Society. Int Orthop 2018;42:401-8.

60. de Campos JRM, White TW. Chest wall stabilization in trauma patients: why, when, and how? J Thorac Dis 2018;10:S951-62.

61. Prins JTH, Van Lieshout EMM, Ali-Osman F, et al. Outcome after surgical stabilization of rib fractures versus nonoperative treatment in patients with multiple rib fractures and moderate to severe traumatic brain injury (CWIS-TBI). J Trauma Acute Care Surg 2021;90:492-500.

62. Beks RB, de Jong MB, Houwert RM, et al. Long-term follow-up after rib fixation for flail chest and multiple rib fractures. Eur J Trauma Emerg Surg 2019;45:645-54.

63. Caragounis EC, Fagevik Olsén M, Pazooki D, et al. 
Surgical treatment of multiple rib fractures and flail chest in trauma: a one-year follow-up study. World J Emerg Surg 2016;11:27.

64. Fagevik Olsén M, Slobo M, Klarin L, et al. Physical function and pain after surgical or conservative management of multiple rib fractures - a follow-up study. Scand J Trauma Resusc Emerg Med 2016;24:128.

65. Marasco SF, Martin K, Niggemeyer L, et al. Impact of rib fixation on quality of life after major trauma with multiple rib fractures. Injury 2019;50:119-24.

66. Peek J, Kremo V, Beks R, et al. Long-term quality of life and functional outcome after rib fracture fixation. Eur J Trauma Emerg Surg 2020. [Epub ahead of print]. doi: 10.1007/s00068-020-01470-6.

67. Gandhi RR, Overton TL, Haut ER, et al. Optimal timing of femur fracture stabilization in polytrauma patients: A practice management guideline from the Eastern Association for the Surgery of Trauma. J Trauma Acute Care Surg 2014;77:787-95.

68. Klestil T, Röder C, Stotter C, et al. Impact of timing of surgery in elderly hip fracture patients: a systematic review and meta-analysis. Sci Rep 2018;8:13933.

69. Orosz GM, Magaziner J, Hannan EL, et al. Association of timing of surgery for hip fracture and patient outcomes. JAMA 2004;291:1738-43.

70. Giannoudis PV, Papakostidis C, Roberts C. A review of the management of open fractures of the tibia and femur. J Bone Joint Surg Br 2006;88:281-9.

71. Vallier HA, Cureton BA, Ekstein C, et al. Early definitive stabilization of unstable pelvis and acetabulum fractures reduces morbidity. J Trauma 2010;69:677-84.

72. Giannoudis PV, Veysi VT, Pape HC, et al. When should we operate on major fractures in patients with severe head injuries? Am J Surg 2002;183:261-7.

73. DuBose J, Inaba K, Okoye O, et al. Development of posttraumatic empyema in patients with retained hemothorax: results of a prospective, observational AAST study. J Trauma Acute Care Surg 2012;73:752-7.

74. Majercik S, Vijayakumar S, Olsen G, et al. Surgical stabilization of severe rib fractures decreases incidence of retained hemothorax and empyema. Am J Surg 2015;210:1112-6; discussion 1116-7.

75. Pieracci FM, Coleman J, Ali-Osman F, et al. A multicenter evaluation of the optimal timing of surgical stabilization of rib fractures. J Trauma Acute Care Surg 2018;84:1-10.

76. Thiels CA, Aho JM, Naik ND, et al. Infected hardware after surgical stabilization of rib fractures: Outcomes and management experience. J Trauma Acute Care Surg
2016;80:819-23.

77. Sarani B, Allen R, Pieracci FM, et al. Characteristics of hardware failure in patients undergoing surgical stabilization of rib fractures: A Chest Wall Injury Society multicenter study. J Trauma Acute Care Surg 2019;87:1277-81.

78. Althausen PL, Shannon S, Watts C, et al. Early surgical stabilization of flail chest with locked plate fixation. J Orthop Trauma 2011;25:641-7.

79. Iqbal HJ, Alsousou J, Shah S, et al. Early Surgical Stabilization of Complex Chest Wall Injuries Improves Short-Term Patient Outcomes. J Bone Joint Surg Am 2018;100:1298-308.

80. Su YH, Yang SM, Huang CH, et al. Early versus late surgical stabilization of severe rib fractures in patients with respiratory failure: A retrospective study. PLoS One 2019; 14:e0216170.

81. Harrell KN, Jean RJ, Dave Bhattacharya S, et al. Late Operative Rib Fixation is Inferior to Nonoperative Management. Am Surg 2020;86:944-9.

82. Otaka S, Aso S, Matsui H, et al. Effectiveness of surgical fixation for rib fractures in relation to its timing: a retrospective Japanese nationwide study. Eur J Trauma Emerg Surg 2020. [Epub ahead of print]. doi: 10.1007/ s00068-020-01548-1.

83. Otaka S, Aso S, Matsui H, et al. Early Versus Late Rib Fixation in Patients With Traumatic Rib Fractures: A Nationwide Study. Ann Thorac Surg 2020;110:988-92.

84. Chen Zhu R, de Roulet A, Ogami T, et al. Rib fixation in geriatric trauma: Mortality benefits for the most vulnerable patients. J Trauma Acute Care Surg 2020;89:103-10.

85. Pieracci FM, Leasia K, Hernandez MC, et al. Surgical stabilization of rib fractures in octogenarians and beyondwhat are the outcomes? J Trauma Acute Care Surg 2021;90:1014-21.

86. Lawrence JE, Fountain DM, Cundall-Curry DJ, et al. Do Patients Taking Warfarin Experience Delays to Theatre, Longer Hospital Stay, and Poorer Survival After Hip Fracture? Clin Orthop Relat Res 2017;475:273-9.

87. Cha YH, Ha YC, Yoo JI, et al. Effect of causes of surgical delay on early and late mortality in patients with proximal hip fracture. Arch Orthop Trauma Surg 2017;137:625-30.

88. Pieracci FM, Leasia K, Whitbeck S. Barriers to conducting a multi-center randomized controlled trial of surgical stabilization of rib fractures (and how to overcome them). J Thorac Dis 2019;11:S1049-60.

89. Shao J, Zhang H, Yin B, et al. Risk factors for surgical site infection following operative treatment of ankle 
fractures: A systematic review and meta-analysis. Int J Surg 2018;56:124-32.

90. Hopper AN, Jamison MH, Lewis WG. Learning curves in surgical practice. Postgrad Med J 2007;83:777-9.

Cite this article as: Prins JTH, Wijffels MME, Pieracci FM. What is the optimal timing to perform surgical stabilization of rib fractures? J Thorac Dis 2021;13(Suppl 1):S13-S25. doi: 10.21037/jtd-21-649
91. Bauman ZM, Grams B, Yanala U, et al. Rib fracture displacement worsens over time. Eur J Trauma Emerg Surg 2020. [Epub ahead of print]. doi: 10.1007/s00068020-01353-w. 